\title{
Faun tail: a rare cutaneous sign of spinal dysraphism
}

\author{
Gülcan Saylam Kurtipek ${ }^{1}$, Fatma Göksin Cihan², Vefa Öner ${ }^{3}$, Arzu Ataseven ${ }^{1}$ İlkay Özer ${ }^{1}$, Zahide Akman ${ }^{1}$
}

\begin{abstract}
Faun tail is a triangle-shaped hypertrichosis of the lumbosacral region. It is a rare condition and it can be a cutaneous marker of underlying spinal cord anomaly. We report on a 17-year-old female patient with hypertrichosis on the lumbosacral area since birth that was later diagnosed with tethered cord in magnetic resonance imaging.
\end{abstract}

Keywords: faun tail, hypertrichosis, tethered cord

Received: 12 February 2015 | Returned for modification: 22 February 2015 | Accepted: 1 March 2015

\section{Introduction}

Faun tail is an abnormal congenital hypertrichosis of the lumbosacral region characterized by a triangular-shaped area of thick hair of various lengths. Faun tail is rarely seen and indicates underlying spinal cord anomalies (1). Spinal dysraphism is a medical term that refers to neurological disorders related to malformations of the spinal cord, which can arise from failure in the closure of caudal neuropores at the end of the fourth week of embryological life. When these anomalies exist, increased local hair growth, presence of a sinus orifice, hemangioma, and the formation of lipoma and a sacral dimple can be seen as some of the cutaneous markers (2). Because it is a rarely seen entity, we present this case, a 17-year-old female with lumbosacral hypertrichosis that was diagnosed with tethered cord by using magnetic resonance imaging.

\section{Case report}

A 17-year-old female presented to our clinic with a complaint of a triangular-shaped hypertrichosis consisting of coarse, thick hairs in the lumbosacral area since birth. It appeared that no comprehensive evaluation had been performed previously for the patient's complaint. A dense hypertrichotic area with coarse, thick hair was observed in the lumbosacral region on dermatological examination (Figure 1). Because of the possibility of the presence an underlying spinal cord anomaly, magnetic resonance (MR) imaging was ordered. MR assessment revealed that the conus medullaris ended at the L3 vertebra superior end-plate level (tethered cord; Figure 2). Neurological evaluation demonstrated no neurological deficit arising from the tethered cord. The patient was referred for epilatory hair removal because of the cosmetic issues.

\section{Discussion}

Congenital localized hypertrichosis, called faun tail, is a hypertrichosis characterized by localized thick, coarse hair growth in the lumbosacral area, and there is a possible association with spinal defects. This type of hypertrichosis was present at birth and should be differentiated from the hirsutism associated with hormonal changes (3). The most common spinal defects are spina bifida, dias- tematomyelia, tethered cord, intraspinal lipomas, dermal sinuses, cutaneous aplasia, lipomeningomyelocele, and hemangiomas (4-7).

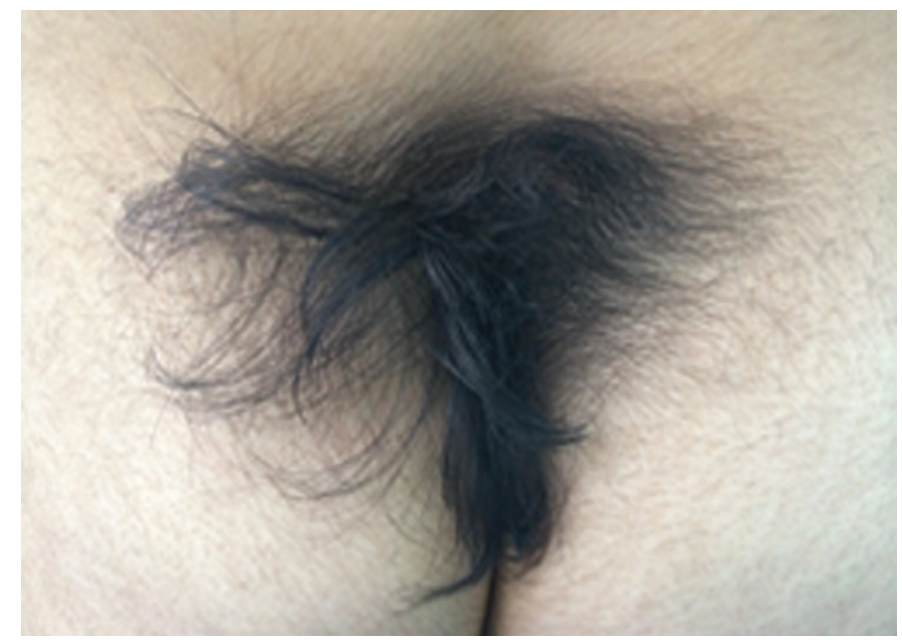

Figure 1 | A dense hypertrichotic area with coarse, thick hair was observed in the lumbosacral region.

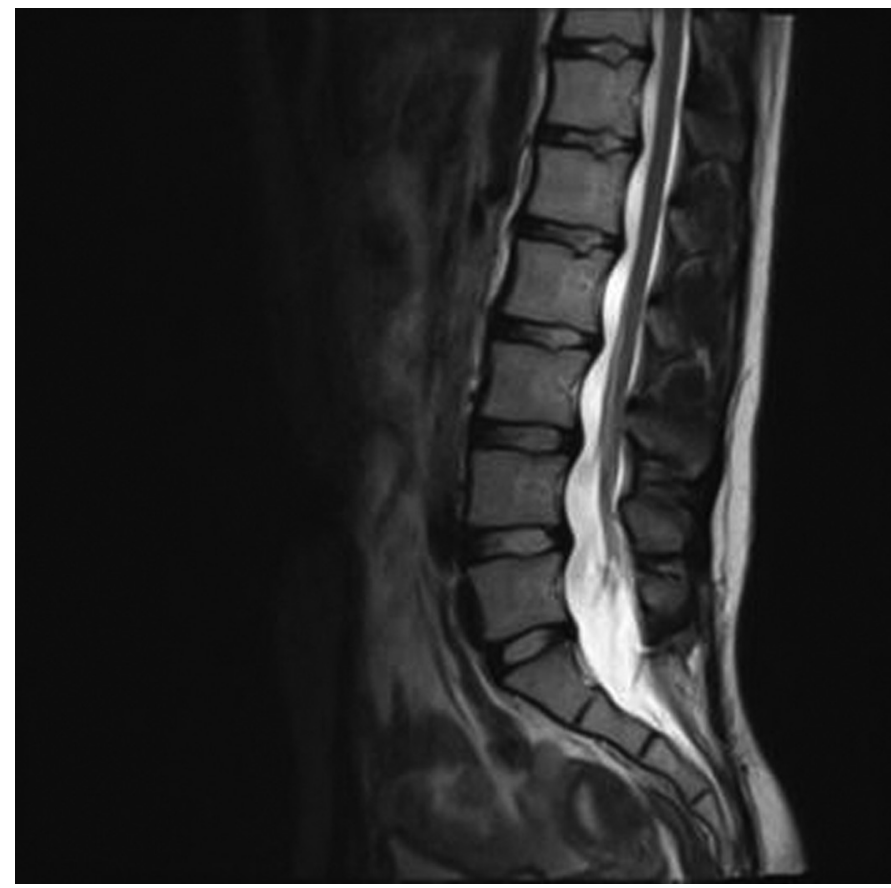

Figure 2 | Conus medullaris ended at L3 vertebra superior end-plate level (tethered cord).

${ }^{1}$ Department of Dermatology, Konya Training and Research Hospital, Konya, Turkey. ${ }^{2}$ Department of Family Practice, Necmettin Erbakan University, Faculty of Medicine, Konya, Turkey. ${ }^{3}$ Department of Radiology, Konya Training and Research Hospital, Konya, Turkey. $\bowtie$ Corresponding author: gsaylamkurtipek@yahoo.com 
Some case reports were previously published, but no studies with large series exist. All of these articles demonstrated and emphasized that there could be an association with spinal cord anomalies, that dermatologists were the physicians that first diagnosed patients with faun tail, and that neurological and neurosurgical consultations were required in order to assess the presence of neurological deficit and give a neurological diagnosis.

Tethered spinal cord syndrome (TSCS) arises from abnormal stretching of the spinal cord caused by congenital or acquired pathologies and is characterized by a progressive neurological deficit. Tethered cord syndrome is also termed tight filum terminale or filum terminale syndrome. Motor deficit, urological symptoms, progressive spinal deformities including scoliosis, trophic ulcers, and dermatological symptoms are commonly seen during childhood; TSCS usually presents with perineal and perianal pain, urological symptoms, and motor deficit in the adult population (8). Final diagnosis of TSCS is made with MR imaging. It is possible to determine low-lying conus medullaris, tight filum termi- nale, and other congenital abnormalities (hydromyelia) with MR imaging (9). After diagnosis, regular neurological follow-up is needed.

Because hypertrichosis is composed of thick and coarse hair, it has a psychosocial impact on the patient's life. Possible treatment options are shaving, bleaching, waxing, chemical and physical depilation, electrolysis, IPL, and laser hair removal (10, 11). Because laser provides effective, easy, and safe hair removal with permanent results, it has been widely used in recent years. The most common laser types used for hair removal are diode, ruby, Nd:Yag, and Alexandrite (12).

We also referred our patient to a laser hair removal center for cosmetic reasons.

Faun tail is not only a neurological and neurosurgical disorder possibly associated with spinal anomalies, but also a problem with psychosomatic components. This case report is presented to emphasize the rarity of the condition and as a possible source of cosmetic and psychological distress for the patient's life.

\section{References}

1. Polat M, Polat F, Oztaş P, Kaya C, Alli N. Faun tail: a rare cutaneous marker of spinal dysraphism. Skinmed. 2010;8:181-3.

2. Yamini M, Sridevi KS, Babu NP, Chetty NG. Faun tail nevus. Indian Dermatol Online J. 2011;2:23-4.

3. İzci Y, Gönül M, Gönül E. The diagnostic value of skin lesions in split cord malformations. J Clin Neurosci. 2007;14:860-3.

4. Antony FC, Holden CA. Diffuse hypertrichosis and faun-tail naevus as cutaneous markers of spinal dysraphism. Clin Exp Dermatol. 2002;27:645-8.

5. Birol A, Bademci G. Faun tail: diagnosis of occult spinal dysraphism with a rare cutaneous marker. J Dermatol. 2004;31:251-2.

6. Calikoğlu E, Oztaş P, Yavuzer Anadolu R, Catal F, Görpelioğlu C. Faun tail with aplasia cutis congenita and diastematomyelia. Dermatology. 2004;209:333-4.
7. Brar BK, Mahajan BB, Mittal J. The longest faun tail forming dreadlocks with underlying spina bifida occulta. Dermatol Online J. 2013;19:12.

8. Tatı M, Güzel A, Karadağ Ö. Gergin Omurilik Sendromu C. Ü. Tıp Fakültesi Dergisi. 2004;26:149-52. Turkish.

9. Kılıçkesmez O, Barut Y, Taşdemiroglu E. MRI features of adult tethered cord syndrome. Tanı Girişim Radyol. 2003;9:295-301.

10. Lee HI, Rho YK, Kim BJ, Kim MN. A case of faun tail naevus treated by intense pulsed light. Ann Dermatol. 2009;21:147-9.

11. Özdemir M, Balevi A, Engin B, Güney F, Tol H Treatment of faun-tail naevus with intense pulsed light. Photomed Laser Surg. 2010;28:435-8.

12. Kaptanoglu AF, Kaptanoglu E. Faun tail nevus and spinal dysraphism: cosmetic improvement with alexandrite laser epilation. Ann Dermatol. 2011;23(Suppl 3):S296-8. 